\title{
Co-expression of ATP binding cassette transporters is associated with poor prognosis in acute myeloid leukemia
}

\author{
BEI LIU ${ }^{1,2^{*}}$, LI-JUN LI ${ }^{1 *}$, XIA GONG ${ }^{3}$, WEI ZHANG ${ }^{4}$, HUI ZHANG $^{1}$ and LI ZHAO ${ }^{1,4}$ \\ ${ }^{1}$ The First Clinical Medical College of Lanzhou University; Departments of ${ }^{2}$ Hematology and ${ }^{3}$ Special Medicine; \\ ${ }^{4}$ Central Laboratory, The First Affiliated Hospital of Lanzhou University, Lanzhou, Gansu 730000, P.R. China
}

Received September 9, 2017; Accepted February 13, 2018

DOI: $10.3892 / 01.2018 .8095$

\begin{abstract}
Chemotherapy failure remains a challenge when treating patients with acute myeloid leukemia (AML), who often suffer from persistent or relapsed disease. The multidrug resistance (MDR) mediated by efflux transporters of the ATP binding cassette $(\mathrm{ABC})$ superfamily is a major obstacle for successful chemotherapy. The present study aimed to elucidate whether the expression of $\mathrm{ABC}$ transporters was associated with prognostic factors and responses to chemotherapy in patients with AML, with particular focus on whether co-expression of multiple $\mathrm{ABC}$ transporters resulted in a worse prognosis. In the present study, the mRNA expression levels of $A B C$ transporters $A B C B 1, A B C B 4, A B C C 1, A B C C 4$ and $A B C G 2$ in bone marrow (BM) mononuclear cell (MNC) samples from 96 de novo patients with AML and in the peripheral blood (PB) MNC samples from 22 normal individuals were investigated using reverse transcription-quantitative polymerase chain reaction analysis. It was revealed that $A B C B 1, A B C C 1, A B C C 4$ and $A B C G 2$ were expressed at higher levels in patients with AML compared with normal individuals, whereas $A B C B 4$ had a lower expression level. The expression of $A B C B 4$ in patients with AML was significantly lower than in normal individuals $(\mathrm{P}<0.001)$. Patients risk status was associated with $A B C B 1(\mathrm{P}=0.037), A B C C 1(\mathrm{P}=0.047), A B C C 4(\mathrm{P}=0.015)$ and $A B C G 2(\mathrm{P}=0.027)$. The 4 genes were expressed a significantly higher levels in the poor response group compared with the good response group $(A B C B 1, \mathrm{P}=0.014 ; A B C C 1, \mathrm{P}=0.021$; $A B C C 4, \mathrm{P}=0.005 ; A B C G 2, \mathrm{P}=0.009$ ). The overexpression of the $4 \mathrm{ABC}$ transporters and the complete remission rate were inversely correlated $(\mathrm{P}<0.001)$. These results suggest that the
\end{abstract}

Correspondence to: Professor Li Zhao, Central Laboratory, The First Affiliated Hospital of Lanzhou University, 1 Donggang Road (West), Lanzhou, Gansu 730000, P.R. China

E-mail: zhaoli@lzu.edu.cn

${ }^{*}$ Contributed equally

Key words: co-expression, $\mathrm{ABC}$ transporter, acute myeloid leukemia, multidrug resistance, response to chemotherapy co-expression of multiple $\mathrm{ABC}$ transporters may contribute to a worse prognosis in AML.

\section{Introduction}

Multidrug resistance (MDR) is an important strategy employed by cancer cells and interferes with the success of acute myeloid leukemia (AML) chemotherapy. One of the common mechanisms of MDR is the overexpression of ATP binding cassette $(\mathrm{ABC})$ transporters in cancer cells, such as P-glycoprotein (P-gp-1/MDR1/ABCB1), MDR 3 (P-gp-3/MDR3/ABCB4), MDR-associated protein 1 (MRP1/ABCC1), MDR-associated protein 4 (MRP4/ABCC4) and breast cancer resistance protein (BCRP/ABCG2). ABCB1 was the first anticancer drug pump to be identified and is the best studied $A B C$ drug efflux transporter to date. Expression of $A B C B 1$ has long been identified as an independent, unfavorable prognostic factor of both complete remission and survival in patients with AML $(1,2)$. A new member of the $A B C$ superfamily, $A B C B 4$ possesses $80 \%$ homology to $A B C B 1$. It is suggested that $A B C B 4$ plays a supplementary role to $A B C B I$ in chronic lymphocytic leukemia (CLL) drug resistance (3) and might have an independent role in MDR in chronic lymphoproliferative disorders (CLPDs) $(4,5)$. To date, however, $A B C B 4$ expression has rarely been studied in AML. Our previous study proved that expression of $A B C C 4$ induced resistance in the adriamycin-resistant AML cell line K562/ADR and that lentivirus-mediated knockdown of $A B C C 4$ might enhance sensitivity to adriamycin (6). The other $\mathrm{ABC}$ transporters mentioned above, $A B C C 1$ and $A B C G 2$, mediating the export of a very wide variety of antineoplastic drugs from different drug classes were reported to associated with AML $(2,7)$. When such substrate drugs enter the cancer cells from the blood, they are immediately pumped back into the blood due to the high level of MDR protein transporters in the plasma membrane (8), which limits the prolonged and effective use of chemotherapeutic drugs $(9,10)$. There is increasing evidence showing that a number of $A B C$ transporters can transport the same substrates, and, perhaps more importantly, that the phenomenon of co-transport of multiple $\mathrm{ABC}$ transporters can significantly increase substrates transportation efficiency (11).

The present study aimed to analyze the correlation between the co-expression of $\mathrm{ABC}$ transporters and prognosis in AML. The association between the expression of $\mathrm{ABC}$ transporters 
Table I. Characteristics of de novo AML patients $(\mathrm{n}=96)$.

\begin{tabular}{|c|c|c|c|c|}
\hline Characteristic & $\begin{array}{l}\text { Good response } \\
\qquad(n=36)\end{array}$ & $\begin{array}{l}\text { Poor response } \\
\qquad(n=38)\end{array}$ & $\begin{array}{c}\text { PR } \\
(n=17)\end{array}$ & $\begin{array}{l}\text { Early mortality } \\
\qquad(\mathrm{n}=5)\end{array}$ \\
\hline \multicolumn{5}{|l|}{ Age, years } \\
\hline Median (range) & $44.5(7-72)$ & $44(10-82)$ & $51(4-77)$ & $52(45-59)$ \\
\hline \multicolumn{5}{|l|}{ Sex } \\
\hline Male:female & $20: 16$ & 19:19 & $11: 6$ & $3: 2$ \\
\hline \multicolumn{5}{|c|}{ WBC at diagnosis $\left(\times 10^{9} / 1\right)$} \\
\hline Median (range) & $18.17(0.33-247)$ & $10(0.56-273.7)$ & $7.37(0.67-98.45)$ & $189(10.64-337.3)$ \\
\hline \multicolumn{5}{|l|}{ Sex } \\
\hline Male:female & $20: 16$ & 19:19 & $11: 6$ & $3: 2$ \\
\hline \multicolumn{5}{|c|}{ WBC at diagnosis $\left(\mathrm{x} 10^{9} / 1\right)$} \\
\hline Median (range) & $18.17(0.33-247)$ & $10(0.56-273.7)$ & $7.37(0.67-98.45)$ & $189(10.64-337.3)$ \\
\hline \multicolumn{5}{|l|}{ Cytogenetics $^{\mathrm{a}}$} \\
\hline Favorable & 6 & 0 & 1 & 0 \\
\hline Intermediate & 27 & 22 & 9 & 5 \\
\hline Unfavorable & 1 & 15 & 3 & 0 \\
\hline Not available & 2 & 1 & 4 & 0 \\
\hline \multicolumn{5}{|c|}{ FLT3-ITD mutation } \\
\hline$(+)$ & 0 & 10 & 1 & 1 \\
\hline$(-)$ & 35 & 28 & 15 & 4 \\
\hline Not available & 1 & 0 & 1 & 0 \\
\hline \multicolumn{5}{|l|}{$c-K I T$ mutation } \\
\hline$(+)$ & 3 & 5 & 0 & 0 \\
\hline$(-)$ & 32 & 33 & 16 & 5 \\
\hline Not available & 1 & 0 & 1 & 0 \\
\hline \multicolumn{5}{|l|}{ NPM1 mutation } \\
\hline$(+)$ & 4 & 5 & 2 & 1 \\
\hline$(-)$ & 31 & 33 & 14 & 4 \\
\hline Not available & 1 & 0 & 1 & 0 \\
\hline \multicolumn{5}{|c|}{ Biallelic $C E B P A$ mutation } \\
\hline$(+)$ & 3 & 6 & 3 & 1 \\
\hline$(-)$ & 32 & 32 & 13 & 4 \\
\hline Not available & 1 & 0 & 1 & 0 \\
\hline
\end{tabular}

${ }^{a}$ Cytogenetics stratification based on NCCN Guidelines Version 2.2014 Acute Myeloid Leukemia. Favorable: inv(16) or $\mathrm{t}(16 ; 16), \mathrm{t}(8 ; 21)$, $\mathrm{t}(15 ; 17)$. Intermediate: Normal cytogenetics, $+8, \mathrm{t}(9 ; 11)$, other non-defined. Adverse: Complex ( $\geq 3$ clonal chromosomal abnormalities), monosomal karyotype-5, 5q-, -7, 7q-, 11q23-non. t(9;11), inv(3), t(3;3), t(6;9), t(9;22). FLT3-ITD, FMS-like tyrosine kinase 3- internal tandem duplication; NPM1, nucleophosmin 1; CEBPA, CCAAT/enhancer-binding protein $\alpha$; AML, acute myeloid leukemia; PR, partial remission; WBC, white blood cell.

and clinical factors such as age, sex, white blood cell (WBC) count, cytogenetic and genetic features, as well as response to chemotherapy, was also investigated. In this way, we attempted to identify new indicators in MDR patients that can effectively overcome MDR in the future.

\section{Materials and methods}

Patients and samples. The 96 de novo AML patient (M3 excluded) bone marrow (BM) samples and 28 normal peripheral blood (PB) samples came from the Hematology Department of First Hospital of Lanzhou University between
August 2013 and August 2016. The initial diagnoses and classifications of AML were confirmed by MICM. The main patient characteristics are summarized in Table I. All patients were treated with standard chemotherapy. The follow-up time was 9 months. Complete remission (CR) was defined as the recovery of BM morphology, including $<5 \%$ blasts, an absolute neutrophil count $>1 \times 10^{9} / 1$, a platelet count $\geq 100 \times 10^{9} / 1$, and no evidence of extramedullary leukemia. Partial remission (PR) was defined as a decrease in at least $50 \%$ in the percentage of blasts (down to between 5 and 25\%) in the BM aspirate and the normalization of blood counts. Non-remission (NR) was defined as a marrow blasts percentage did not decrease to $25 \%$ 
Table II. Sequences of primers used for reverse transcription-polymerase chain reaction.

\begin{tabular}{lllc}
\hline Gene name & \multicolumn{1}{c}{ Forward primer $\left(5^{\prime} \sim 3^{\prime}\right)$} & \multicolumn{1}{c}{ Reverse primer (5' 3') } & Amplicon size (bp) \\
\hline$\beta$-actin & GGAGATTACTGCCCTGGCTCCTA & GACTCATCGTACTCCTGCTTGCTG & 150 \\
A BCB1 & GGAAAGTGCTGCTTGATGGC & AGGCATGTATGTTGGCCTCC & 195 \\
$A B C B 4$ & AACCCCAAGATCCTTCTGCT & GGACCGTAGACAGTCGGTGT & 136 \\
$A B C C 1$ & TTACTCATTCAGCTCGTCTTGTC & CAGGGATTAGGGTCGTGGAT & 80 \\
$A B C C 4$ & CATGACTTGGACACGGTAACTGTTG & TCAGGAATGTCGGTTAGAGGTTTG & 88 \\
A $B C G 2$ & CATGGTGTATAGACGCCCTGAC & GTTCCCAAATTGATGTTGTGACAGA & 95 \\
\hline
\end{tabular}

$A B C B 1$, P-glycoprotein; $A B C B 4$, multidrug resistance 3; $A B C C 1$, multidrug resistance-associated protein 1; $A B C C 4$, multidrug resistanceassociated protein $4 ; A B C G 2$, breast cancer resistance protein.

or below after induction chemotherapy. Early death was defined as death before completion of the induction chemotherapy cycle (12). The patients who reached CR and maintained relapse free survivals (RFS) for $>9$ months were regarded as good response to chemotherapy. In contrast, people who showed NR or relapsed at any time during the 9 months post treatment were considered as poor response to chemotherapy. All procedures performed involving human participants were in accordance with both the ethical standards of the institutional and/or national research committee and with the 1964 Helsinki declaration and its later amendments, or comparable ethical standards.

Real-time PCR detection of ABC transporter expression. For these experiments, BM mononuclear cells (MNCs) from patients and $\mathrm{PB}$ MNCs from normal individuals were separated using Ficoll Hypaque ${ }^{\circledR}$ (Sigma-Aldrich; Merck KGaA, Darmstadt, Germany) gradient centrifugation, and total RNAs were extracted using TRIzol Reagent (TransStart, Beijing, China) following the manufacturer's instructions. RNA was reverse transcribed using a reverse transcription kit (Takara Biotechnology Co., Ltd., Dalian, China) according to the manufacturer's recommendations. The cDNA was stored at $-20^{\circ} \mathrm{C}$ and $5-\mathrm{ml}$ aliquots of the cDNA product diluted in a $50-\mathrm{ml}$ volume of DEPC-treated RNase-free ultra-pure water to be used for each real-time amplification reaction.

Real-time PCR was performed with SYBR-Green I qPCR SuperMix (TransStart) on the RocheLightCycler ${ }^{\circledR} 480$ (Roche Diagnostics, Basel, Switzerland) according to the manufacturer's recommendations. Each 13-ml PCR contained $2 \mathrm{ml}$ of diluted cDNA $\left(10^{-1} \mathrm{M}\right)$. Real-time PCR amplification was performed with the following parameters: $30 \mathrm{sec}$ at $94^{\circ} \mathrm{C}$ and then 40 cycles of $5 \mathrm{sec}$ at $94^{\circ} \mathrm{C}, 15 \mathrm{sec}$ at $61^{\circ} \mathrm{C}$ and $10 \mathrm{sec}$ at $72^{\circ} \mathrm{C}$. An additional cycle of $1 \mathrm{sec}$ at $95^{\circ} \mathrm{C}, 15 \mathrm{sec}$ at $61^{\circ} \mathrm{C}$, $15 \mathrm{sec}$ at $95^{\circ} \mathrm{C}$ was performed at the end of the reaction to generate the dissociation curve of the amplicon to ensure a single and specific product with the corresponding melting temperature was produced. A negative water control without cDNA for each PCR was used to check for reagent contamination. A housekeeping gene ( $\beta$-actin) was amplified from the same samples to ensure all samples were used at an equal baseline. All ABC transporter and housekeeping gene levels were measured in triplicate. The primer sequences for $\beta$-actin,
$A B C B 1, A B C B 4, A B C C 1, A B C C 4$ and $A B C G 2$ are listed in Table II. The relative quantification of the 5 genes was performed using the $2^{-\Delta \Delta \mathrm{Ct}}$ method.

Treatment protocol. Induction chemotherapy for adult patients included continuous infusion of standard-dose cytarabine $\left(100-200 \mathrm{mg} / \mathrm{m}^{2}\right)$ for 7 days, with idarubicin $\left(8-12 \mathrm{mg} / \mathrm{m}^{2}\right)$ or daunorubicin $\left(45-60 \mathrm{mg} / \mathrm{m}^{2}\right)$ for 3 days. Induction chemotherapy for children included continuous infusion of standard-dose cytarabine $\left(100-200 \mathrm{mg} / \mathrm{m}^{2}\right)$ for 7 days, with idarubicin $\left(10 \mathrm{mg} / \mathrm{m}^{2}\right)$ or daunorubicin $\left(40 \mathrm{mg} / \mathrm{m}^{2}\right)$ administered for 3 days and etoposide $\left(100 \mathrm{mg} / \mathrm{m}^{2}\right)$ dministered on days 5-7.

Post-induction chemotherapy for adult patients included middle-dose cytarabine $\left(0.5-1 \mathrm{~g} / \mathrm{m}^{2}\right)$ every $12 \mathrm{~h}$ for 3 days, with mitoxantrone $\left(8-10 \mathrm{mg} / \mathrm{m}^{2}\right)$ daunorubicin $\left(45-60 \mathrm{mg} / \mathrm{m}^{2}\right)$ or idarubicin $\left(8-12 \mathrm{mg} / \mathrm{m}^{2}\right)$ given for 3 days, in turn for highdose cytarabine $\left(3 \mathrm{~g} / \mathrm{m}^{2}\right)$ every $12 \mathrm{~h}$ for 3 days. Post-induction chemotherapy for adult patients included middle-dose cytarabine $\left(0.5-1 \mathrm{~g} / \mathrm{m}^{2}\right)$ every $12 \mathrm{~h}$ for 3 days, with daunorubicin $\left(40 \mathrm{mg} / \mathrm{m}^{2}\right)$ for 3 days and etoposide $\left(100 \mathrm{mg} / \mathrm{m}^{2}\right)$ for 2 days, in turn for high-dose cytarabine $\left(1 \mathrm{~g} / \mathrm{m}^{2}\right)$ every $12 \mathrm{~h}$ for 4 days. Central nervous system (CNS) prophylaxis was regularly administered.

Statistical analysis. All calculations were performed with the IBM SPSS Statistics 21.0 program (IBM Corp., Armonk, NY, USA) and graphs were made using GraphPad Prism 5 software (GraphPad Software, Inc., La Jolla, CA, USA). Since the levels of $\mathrm{ABC}$-transporter expression did not follow normal distributions, the expression of the transporters in different groups of patients was compared using the Mann-Whitney test for 2 groups and the Kruskal-Wallis test for $>2$ groups. Spearman's rho method was used to test the correlation between numerical variables. The comparison of proportions was performed using Fisher's exact test. All P-values were two-sided. P $<0.05$ was considered significant.

\section{Results}

Expression of $A B C$ transporter genes. The mRNA expression levels of $A B C B 1, A B C B 4, A B C C 1, A B C C 4$ and $A B C G 2$ in 96 de novo AML patients and 22 normal individuals were 


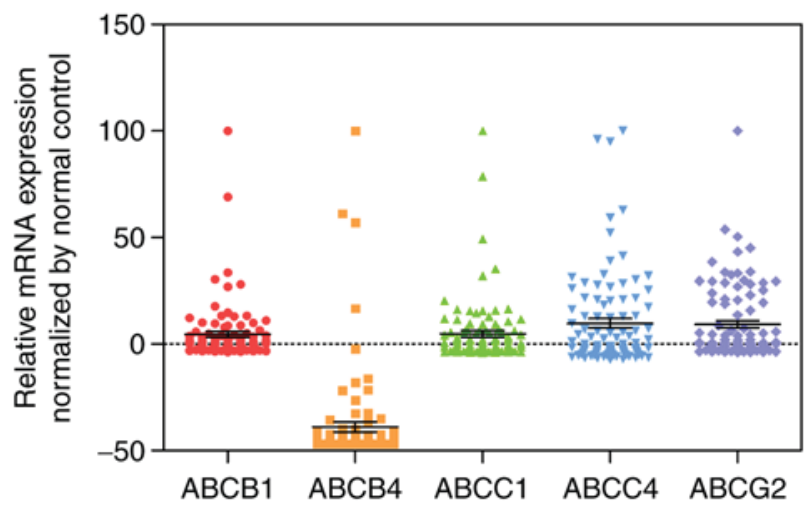

Figure 1. Relative mRNA expression of ABC transporter genes. Expression levels of the $\mathrm{ABC}$ transporters in the acute myeloid leukemia group were normalized to those of the normal control group. ABC, ATP binding cassette.

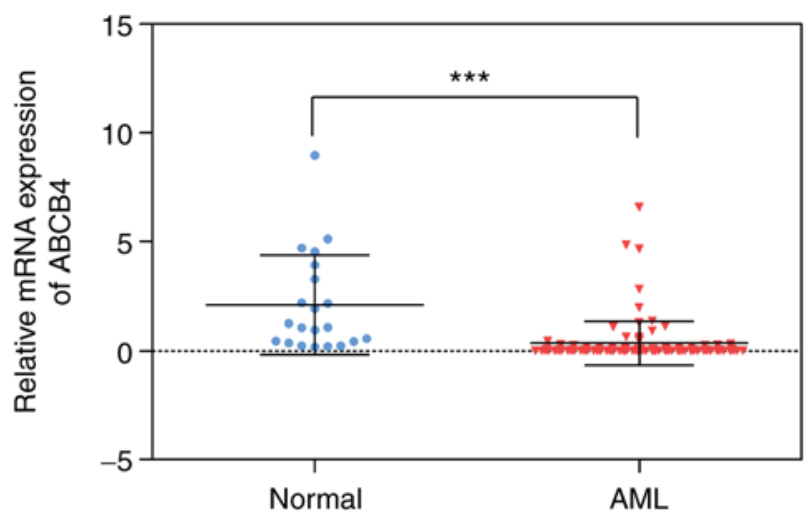

Figure 2. ABCB4 mRNA expression in de novo AML patients compared to normal controls. ${ }^{* * *} \mathrm{P}<0.001$. AML, acute myeloid leukemia; ABC, ATP binding cassette.

determined using real-time PCR. The expression levels of the $\mathrm{ABC}$ transporters in the AML group were normalized to those of the normal control group, showing inconsistent trends among the $\mathrm{ABC}$ transporter genes. The expression of $A B C B 1$, $A B C C 1, A B C C 4$ and $A B C G 2$ was high in AML, while that of $A B C B 4$ was the opposite (Fig. 1).

Low expression of $A B C B 4$ transporter gene. $A B C B 4$ mRNA expression was significantly lower in AML patients than in normal individuals $(\mathrm{P}<0.001)$ (Fig. 2).

Clinical characteristics of de novo AML patients and associations of $A B C B 1, A B C C 1, A B C C 4$ and $A B C G 2$ expression levels with these characteristics. Although the expression levels of $A B C B 1, A B C C 1, A B C C 4$ and $A B C G 2$ in $\mathrm{AML}$ patients were all higher than in normal individuals, those differences disappeared when patients were grouped based on clinical factors (Table III). Patient parameters including age, sex, WBC count, cytogenetics, FLT3-ITD, c-KIT, NPMI and biallelic $C E B P A$ mutation were evaluated as prognostic factors. In general, poor-risk patients expressed a higher level of upregulated $\mathrm{ABC}$ transporters than did favorable-risk patients. According to NCCN guidelines, favorable-risk was defined as having $\operatorname{inv}(16), \mathrm{t}(16 ; 16)$ or $\mathrm{t}(8 ; 21)$ abnormalities, or normal cytogenetics with either an NPMI mutation in the absence of

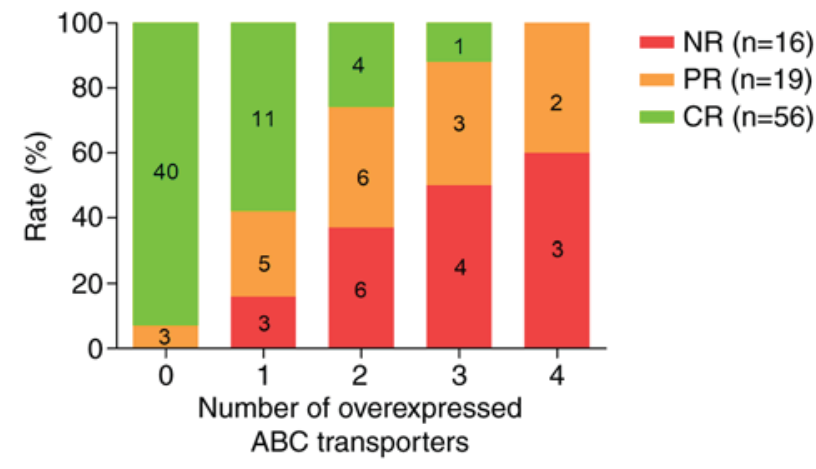

Figure 3. Number of overexpressed $\mathrm{ABC}$ transporters and response to induction chemotherapy $(\mathrm{n}=91)$. ABC, ATP binding cassette; CR, complete remission; PR, partial remission; NR, non-remission.

FLT3-ITD or an isolated biallelic CEBPA mutation. Poor-risk was defined as having a complex karyotype, or normal cytogenetics with a FLT3-ITD mutation. All other abnormalities were defined as intermediate-risk. If a patient had a c-KIT mutatation in addition to either $\mathrm{t}(8 ; 21)$, inv(16), $\mathrm{t}(16 ; 16)$, he/she was classified as intermediate-risk. The 4 genes were all significantly associated with risk status $(A B C B 1, \mathrm{P}=0.037$; $A B C C 1, \mathrm{P}=0.047 ; A B C C 4, \mathrm{P}=0.015 ; A B C G 2, \mathrm{P}=0.027)$. In detail, expression of $A B C B 1, A B C C 1, A B C C 4$ and $A B C G 2$ was markedly higher in the unfavorable cytogenetics group than in the favorable group. Patients who had a FLT3-ITD mutation expressed significantly higher levels of the $A B C B 1$, $A B C C 1, A B C C 4$ and $A B C G 2$ genes than did patients without a FLT3-ITD mutation. ABCC4 and ABCG2 expression was statistically higher in patients with $c$-KIT mutations than in patients without $c$-KIT mutations. However, isolated biallelic CEBPA and NPM1 mutations did not have a clear relationship with $A B C$ expression levels. Noticeably, expression levels of the $4 \mathrm{ABC}$ transporters in the poor response group were markedly higher than in the good response group $(A B C B 1, \mathrm{P}=0.014$; $A B C C 1, \mathrm{P}=0.021 ; A B C C 4, \mathrm{P}=0.005 ; A B C G 2, \mathrm{P}=0.009)$.

Co-expression of $A B C$ transporters. For each $\mathrm{ABC}$ transporter, the cutoff for overexpression was defined as the third quartile of expression for all patients. There were 5 patients who died before completion of the induction therapy cycle. Of the other 91 patients who received the whole induction chemotherapy regimen, $61 \%$ achieved CR, $21 \%$ reached PR and $18 \%$ remained NR. Importantly, the CR rate declined along with an increasing number of overexpressed $A B C$ transporters $(\mathrm{P}<0.001)$ (Fig. 3). None of the 5 patients who overexpressed all 4 of the ABC transporters achieved remission. Specifically, the two PR patients with overexpression of all $4 \mathrm{ABC}$ transporters relapsed quickly. Overall, the number of overexpressed $\mathrm{ABC}$ transporters in a patient can be an independent prognostic factor for achieving complete remission.

Correlation of $A B C$ transporter genes. Using an adjustment for multiple comparisons, there were significant positive correlations between $A B C C 4$ and the other $\mathrm{ABC}$ transporter genes, as well as a significant positive correlation between $A B C C l$ and $A B C G 2$ (Table IV). 
Table III. Associations of ABC transporter expression levels and clinical characteristics with de novo AML patients (n=96).

\begin{tabular}{|c|c|c|c|c|}
\hline Characteristics & $\begin{array}{c}A B C B 1 \\
\text { Mean } \pm \text { SD }\end{array}$ & $\begin{array}{c}A B C C 1 \\
\text { Mean } \pm \text { SD }\end{array}$ & $\begin{array}{c}A B C C 4 \\
\text { Mean } \pm \text { SD }\end{array}$ & $\begin{array}{c}A B C G 2 \\
\text { Mean } \pm \text { SD }\end{array}$ \\
\hline Age (years) & $\mathrm{P}=0.929$ & $\mathrm{P}=0.228$ & $\mathrm{P}=0.177$ & $\mathrm{P}=0.008^{\mathrm{b}}$ \\
\hline$<60$ & $2.35 \pm 4.13$ & $2.21 \pm 4.23$ & $2.42 \pm 3.31$ & $3.06 \pm 4.44$ \\
\hline$\geq 60$ & $3.25 \pm 4.67$ & $1.96 \pm 1.89$ & $3.81 \pm 4.12$ & $8.23 \pm 6.74$ \\
\hline WBC at diagnosis $\left(\mathrm{x} 10^{9} / \mathrm{l}\right)$ & $\mathrm{P}=0.820$ & $\mathrm{P}=0.025^{\mathrm{a}}$ & $\mathrm{P}=0.730$ & $\mathrm{P}=0.331$ \\
\hline$<30$ & $2.37 \pm 4.17$ & $2.39 \pm 4.17$ & $2.63 \pm 3.53$ & $3.38 \pm 5.02$ \\
\hline$\geq 30$ & $2.23 \pm 4.09$ & $1.33 \pm 3.15$ & $2.06 \pm 2.25$ & $4.15 \pm 5.02$ \\
\hline Cytogenetics & $\mathrm{P}=0.029^{\mathrm{a}}$ & $\mathrm{P}=0.032^{\mathrm{a}}$ & $\mathrm{P}=0.009^{\mathrm{b}}$ & $\mathrm{P}=0.017^{\mathrm{a}}$ \\
\hline Favorable & $2.06 \pm 2.83$ & $0.56 \pm 0.70$ & $0.87 \pm 0.54$ & $0.79 \pm 0.30$ \\
\hline Intermediate & $1.52 \pm 2.27$ & $1.55 \pm 1.70$ & $1.82 \pm 2.43$ & $2.59 \pm 3.51$ \\
\hline Unfavorable & $2.52 \pm 1.95$ & $2.68 \pm 3.12$ & $4.42 \pm 4.44$ & $6.31 \pm 6.76$ \\
\hline FLT-3-ITD & $\mathrm{P}=0.019^{\mathrm{a}}$ & $\mathrm{P}=0.019^{\mathrm{a}}$ & $\mathrm{P}=0.007^{\mathrm{b}}$ & $\mathrm{P}=0.007^{\mathrm{b}}$ \\
\hline$(+)$ & $3.77 \pm 4.76$ & $4.19 \pm 6.16$ & $3.60 \pm 2.35$ & $7.57 \pm 7.30$ \\
\hline$(-)$ & $2.04 \pm 3.77$ & $1.34 \pm 1.59$ & $2.19 \pm 3.00$ & $3.26 \pm 5.25$ \\
\hline$c-K I T$ & $\mathrm{P}=0.158$ & $\mathrm{P}=0.101$ & $\mathrm{P}=0.005^{\mathrm{b}}$ & $\mathrm{P}=0.040^{\mathrm{a}}$ \\
\hline$(+)$ & $2.43 \pm 2.40$ & $2.29 \pm 1.45$ & $5.30 \pm 4.56$ & $10.07 \pm 12.05$ \\
\hline$(-)$ & $2.06 \pm 3.68$ & $1.70 \pm 2.97$ & $2.13 \pm 2.64$ & $3.14 \pm 4.29$ \\
\hline Biallelic $C E B P A$ mutation & $\mathrm{P}=0.327$ & $\mathrm{P}=0.114$ & $\mathrm{P}=0.487$ & $\mathrm{P}=0.337$ \\
\hline$(+)$ & $4.63 \pm 7.77$ & $0.74 \pm 0.68$ & $2.91 \pm 3.10$ & $4.68 \pm 5.38$ \\
\hline$(-)$ & $1.93 \pm 2.71$ & $2.11 \pm 3.54$ & $2.32 \pm 2.91$ & $3.39 \pm 4.70$ \\
\hline NPM1 mutation & $\mathrm{P}=0.456$ & $\mathrm{P}=0.508$ & $\mathrm{P}=0.041^{\mathrm{a}}$ & $\mathrm{P}=0.255$ \\
\hline$(+)$ (in the absence of FLT3-ITD) & $0.95 \pm 0.53$ & $0.82 \pm 0.67$ & $0.62 \pm 0.51$ & $1.05 \pm 0.69$ \\
\hline$(-)$ & $2.11 \pm 3.78$ & $2.00 \pm 3.52$ & $2.35 \pm 2.92$ & $3.07 \pm 3.65$ \\
\hline Risk status & $\mathrm{P}=0.037^{\mathrm{a}}$ & $\mathrm{P}=0.047^{\mathrm{a}}$ & $\mathrm{P}=0.015^{\mathrm{a}}$ & $\mathrm{P}=0.027^{\mathrm{a}}$ \\
\hline Favorable-risk & $1.39 \pm 1.32$ & $0.59 \pm 0.59$ & $1.66 \pm 2.28$ & $2.20 \pm 2.69$ \\
\hline Intermediate-risk & $1.67 \pm 3.08$ & $1.48 \pm 1.59$ & $1.65 \pm 2.59$ & $2.24 \pm 2.95$ \\
\hline Poor-risk & $2.85 \pm 3.46$ & $2.26 \pm 2.27$ & $3.86 \pm 3.69$ & $6.06 \pm 6.37$ \\
\hline Response to chemotherapy & $\mathrm{P}=0.014^{\mathrm{a}}$ & $\mathrm{P}=0.021^{\mathrm{a}}$ & $\mathrm{P}=0.005^{\mathrm{b}}$ & $\mathrm{P}=0.009^{\mathrm{b}}$ \\
\hline Good & $1.04 \pm 0.84$ & $1.21 \pm 2.19$ & $1.92 \pm 3.36$ & $1.83 \pm 2.47$ \\
\hline Poor & $2.82 \pm 3.91$ & $2.34 \pm 3.38$ & $3.85 \pm 3.87$ & $6.08 \pm 6.62$ \\
\hline
\end{tabular}

${ }^{\mathrm{a}} \mathrm{P}<0.05,{ }^{\mathrm{b}} \mathrm{P}<0.01$. AML, acute myeloid leukemia; WBC, white blood cell; FLT3-ITD, FMS-like tyrosine kinase 3- internal tandem duplication; $N P M 1$, nucleophosmin 1; CEBPA, CCAAT/enhancer-binding protein $\alpha$; $A B C B 1$, P-glycoprotein; $A B C B 4$, multidrug resistance 3; $A B C C 1$, multidrug resistance-associated protein $1 ; A B C C 4$, multidrug resistance-associated protein $4 ; A B C G 2$, breast cancer resistance protein.

Table IV. Correlation of $A B C B 1, A B C C 1, A B C C 4$ and $A B C G 2$ transporter genes.

\begin{tabular}{|c|c|c|c|c|}
\hline Gene name & $A B C B 1$ & $A B C C 1$ & $A B C C 4$ & $A B C G 2$ \\
\hline \multirow[t]{2}{*}{$A B C B 1$} & & $\mathrm{R}=-0.039$ & $\mathrm{R}=0.208$ & $\mathrm{R}=0.132$ \\
\hline & & $\mathrm{P}=0.710$ & $\mathrm{P}=0.042^{\mathrm{a}}$ & $P=0.202$ \\
\hline \multirow[t]{2}{*}{$A B C C 1$} & $R=-0.039$ & & $\mathrm{R}=0.282$ & $\mathrm{R}=0.250$ \\
\hline & $\mathrm{P}=0.710$ & & $\mathrm{P}=0.005^{\mathrm{a}}$ & $\mathrm{P}=0.014^{\mathrm{a}}$ \\
\hline \multirow[t]{2}{*}{$A B C C 4$} & $\mathrm{R}=0.208$ & $\mathrm{R}=0.282$ & & $\mathrm{R}=0.559$ \\
\hline & $\mathrm{P}=0.042^{\mathrm{a}}$ & $\mathrm{P}=0.005^{\mathrm{b}}$ & & $\mathrm{P}<0.001^{\mathrm{c}}$ \\
\hline \multirow[t]{2}{*}{$A B C G 2$} & $\mathrm{R}=0.132$ & $\mathrm{R}=0.250$ & $\mathrm{R}=0.559$ & \\
\hline & $\mathrm{P}=0.202$ & $\mathrm{P}=0.014^{\mathrm{a}}$ & $\mathrm{P}<0.001^{\mathrm{c}}$ & \\
\hline
\end{tabular}

${ }^{\mathrm{a}} \mathrm{P}<0.05,{ }^{\mathrm{b}} \mathrm{P}<0.01,{ }^{\mathrm{c}} \mathrm{P}<0.001$. There existed significant positive correlation between $A B C C 1$ and $A B C G 2, A B C C 4$ and $A B C B 1, A B C C 4$ and $A B C C 1$, as well as $A B C C 4$ and $A B C G 2$. $A B C B 1$, P-glycoprotein; $A B C B 4$, multidrug resistance $3 ; A B C C 1$, multidrug resistance-associated protein 1; $A B C C 4$, multidrug resistance-associated protein $4 ; A B C G 2$, breast cancer resistance protein. 


\section{Discussion}

A better understanding of the mechanisms of chemotherapy resistance in myeloid leukemia (AML) and further knowledge about the genes whose expression affect the outcome of chemotherapy in advanced disease, may present ways to overcome drug resistance. The present study discusses is whether expression of the $A B C B 1, A B C B 4, A B C C 1, A B C C 4$, and $A B C G 2$ genes is potentially involved in the transportation or redistribution of anticancer agents, and whether the genes are correlated with each other or with clinical factors.

Several studies have suggested that $A B C B 1$ is an independent adverse prognostic factor for response and survival in AML $(13,14)$. A recent study of 123 AML patients showed that patients with lower expression of the $A B C B 1$ and $A B C C l$ genes had better OS and DFS compared with patients who had high expression of these genes (15). The predictive role of $A B C C 4$ has been addressed in childhood AML (16). Similarly, it was demonstrated that $A B C G 2$ mRNA expression is significantly higher in relapsed patients than in CR patients (14). In our study, real-time PCR was used to detect the expression of $\mathrm{ABC}$ transporter genes. We found that the expression of $\mathrm{ABC}$ transporters was associated with most prognostic factors. The patients with unfavorable cytogenetics, FLT3-ITD and $c-K I T$ mutations generally expressed statistically higher ABC transporters levels than did the other risk groups. In contrast Varatharajan et al (15) had proposed that the expression of $A B C B 1$ and $A B C G 2$ was significantly lower in FLT3-ITD mutated AML patients compared with FLT3-ITD negative patients. In their study, the authors reported that the expression of $A B C B 1$ and $A B C G 2$ was markedly higher in NPM1-mutated patients than in unmutated patients, yet our study did not find any statistical differences between the expression levels of $\mathrm{ABC}$ transporters in NPM1-mutated and unmutated cases, except regarding $A B C C 4$. Therefore, to evaluate patient prognosis objectively, we used a combination of cytogenetics and molecular abnormalities to define risk status according to NCCN guidelines as either favorable-risk, intermediate-risk or poor-risk, These groups were positively associated with $\mathrm{ABC}$ transporters expression. Furthermore, $A B C B 1, A B C C 1, A B C C 4$ and $A B C G 2$ can be regarded as independent prognostic factors regarding complete remission in AML.

At this point, many $A B C B 1$ inhibitors have been developed, such as cyclosporine A. However, even when $A B C B 1$ expression was inhibited, multidrug resistance (MDR) was not overcome. We must further pursue this idea that multiple transporters, occasionally with overlapping specificities to a broad range of substrates, are often co-expressed in AML. Rather than a single overexpressed transporter being responsible for MDR, co-expressed transporters cooperate to promote chemoresistance $(2,17-19)$. Selective inhibition of one or two $\mathrm{ABC}$ transporters could be compensated by the remaining transporters (9). According to our study, significant positive correlations exist between the expression of several $\mathrm{ABC}$ transporter genes, particularly for $A B C C 4 / A B C B 1, A B C C 4 / A B C C 1$, $A B C C 4 / A B C G 2$ and $A B C C 1 / A B C G 2$, and these correlations might indicate that the expression of these genes is coordinately regulated. Overexpressing one $\mathrm{ABC}$ transporter might, imply to the overexpression of others. After induction chemotherapy, we found that the more $\mathrm{ABC}$ transporters were overexpressed in de devo AML patients, the less chances the patients had of achieving CR. Researchers suggested this phenomenon occurs due to multifactorial regulation, leading to the reduction of intracellular drug concentrations through modulations in drug influx and efflux (12). In addition, previous study proposed that children with AML who expressed more ABC transporters had a lower chance to respond well to therapy (as measured by the percentage of patient having $<5 \%$ leukemic cells by day 15 of therapy) (18). Based on this situation, it is important to understand the mechanisms of co-expression.

In this prospective study, notably, we found that $A B C B 4$ expression levels were strikingly lower in AML patients compared to those in normal individuals. Kiehl et al (20) showed that $A B C B 4$ was frequently epigenetically silenced in different human cancers. These authors investigated the epigenetic regulation of $A B C B 4$ in 26 human lung, breast, skin, liver, head and neck cancer cells lines and in primary cancers by methylation and expression analysis. Hypermethylation of the $A B C B 4 \mathrm{CpG}$ island promoter occurred in 16 out of 26 (62\%) human cancer cell lines. However, in normal tissues, the chance of hypermethylation was $0 \%$. These authors also suggested that $A B C B 4$ may act as a tumor suppressor in lung cancer. However, their study did not include leukemia cells. Hence the mechanism of $A B C B 4$ expression in AML needs to be confirmed in the future.

In conclusion, we have found that the co-expression of multiple $\mathrm{ABC}$ transporters, rather than a single transporter, plays a vital role in the MDR of AML and contributes to a worse prognosis. Therefore, detecting $\mathrm{ABC}$ transporters in de novo AML patients may help to predict prognosis. Most importantly, ways to inhibit these MDR genes such as through RNA interference of the $A B C$ transporters and the modification of miRNA epigenetic regulation, etc. still need to be explored but should not be limited to the inhibition of a single transporter. Instead, multiple transporters should be targeted to overcome MDR.

In the long term, the mechanism of $\mathrm{ABC}$ transporters expression and the activation of singling pathways as well as targeted therapy strategies should be investigated. Several signaling pathways (such as Wnt/ $\beta$-catenin signaling, Hedgehog, Notch, Akt/PKB) are reported recently (21). Kampen et al (22) suggested that there existed a need to target multiple activated pathways by a research which combined high-throughput approaches for kinomic and proteomic profiling. In addition, a study indicated that $\mathrm{ABC}$ transporters could be regulated by some member of the hedgehog $(\mathrm{Hh})$ signaling pathway, therefore suggested this pathway might be a target to overcome MDR and increase chemotherapeutic response (23). In another studies, it was found that the expression of $A B C B 1, A B C C 1$ and $A B C G 2$ genes was significantly higher in samples with higher Homeodomain-only protein homeobox (HOPX) gene expression (24), thus hypothesized there existed some interaction between HOPX and ABC on some pathway (25). Although our understanding of these mechanisms are limited, novel strategies are now available to allow for larger screening. Whether kinases, Hh, HOPX or other mechanisms and targets, these will be the other potential approaches to inhibit multiple transporters and then overcome MDR.

\section{Acknowledgements}

Not applicable. 


\section{Funding}

This study was supported by the Health Industry Research Project of Gansu Province (grant no. GSWST2012-21).

\section{Authors' contributions}

BL proposed the notion of this research and interpreted the patient data regarding the hematological disease. LL performed the majority of the experiments and was a major contributor in writing the manuscript. XG analyzed the data and designed the figures. WZ and HZ collected and managed the samples. LZ made contributions to the conception of this study, was involved in drafting and revising the manuscript and agreed to be accountable for all aspects of the work.. All authors read and approved the final manuscript to publication.

\section{Ethics approval and consent to participate}

All patients provided written informed consent prior to their inclusion within the study.

\section{Consent for publication}

All patients provided written informed consent for the publication of their data.

\section{Competing interests}

The authors declare that they have no competing interests.

\section{References}

1. Zöchbauer S, Gsur A, Brunner R, Kyrle PA, Lechner K and Pirker R: P-glycoprotein expression as unfavorable prognostic factor in acute myeloid leukemia. Leukemia 8: 974-977, 1994.

2. Marzac C, Garrido E, Tang R, Fava F, Hirsch P, De Benedictis C, Corre E, Lapusan S, Lallemand JY, Marie JP, et al: ATP binding cassette transporters associated with chemoresistance: Transcriptional profiling in extreme cohorts and their prognostic impact in a cohort of 281 acute myeloid leukemia patients Haematologica 96: 1293-1301, 2011.

3. Januchowski R, Wojtowicz K, Andrzejewska M and Zabel M: Expression of MDR1 and MDR3 gene products in paclitaxel-, doxorubicin- and vincristine-resistant cell lines. Biomed Pharmacother 68: 111-117, 2014.

4. Matthews C, Catherwood MA, Larkin AM, Clynes M, Morris TC and Alexander HD: $M D R-1$, but not $M D R-3$ gene expression, is associated with unmutated $\operatorname{IgV}_{\mathrm{H}}$ genes and poor prognosis chromosomal aberrations in chronic lymphocytic leukemia. Leuk Lymphoma 47: 2308-2313, 2006.

5. Drain S, Catherwood MA and Alexander HD: Multidrug resistance in the chronic lymphoproliferative disorders. Leuk Lymphoma 51: 1793-1804, 2010.

6. Liu B, Zhao L, Ma HZ, Zhang W and Jin Y: Knockdown of MRP4 by lentivirus-mediated siRNA improves sensitivity to adriamycin in adriamycin-resistant acute myeloid leukemia cells Chin Sci Bull 57: 90-97, 2012.

7. Yuan X, Koehn J and Hogge DE: Identification of prognostic subgroups among acute myeloid leukemia patients with intermediate risk cytogenetics using a flow-cytometry-based assessment of ABC-transporter function. Leuk Res 39: 689-695, 2015.

8. Cordon-Cardo C, O'Brien JP, Casals D, Rittman-Grauer L, Biedler JL, Melamed MR and Bertino JR: Multidrug-resistance gene (P-glycoprotein) is expressed by endothelial cells at bloodbrain barrier sites. Proc Natl Acad Sci USA 86: 695-698, 1989.
9. Chen Z, Shi T, Zhang L, Zhu P, Deng M, Huang C, Hu T, Jiang L and Li J: Mammalian drug efflux transporters of the ATP binding cassette $(\mathrm{ABC})$ family in multidrug resistance: A review of the past decade. Cancer Lett 370: 153-164, 2016.

10. Cianfriglia M, Mallano A, Ascione A and Dupuis ML: Multidrug transporter proteins and cellular factors involved in free and $\mathrm{mAb}$ linked calicheamicin-gammal (gentuzumab ozogamicin, $\mathrm{GO}$ ) resistance and in the selection of GO resistant variants of the HL60 AML cell line. Int J Oncol 36: 1513-1520, 2010.

11. Schinkel AH and Jonker JW: Mammalian drug efflux transporters of the ATP binding cassette (ABC) family: An overview. Adv Drug Deliv Rev 55: 3-29, 2003.

12. Farawela HM, Khorshied MM, Kassem NM, Kassem HA and Zawam HM: The clinical relevance and prognostic significance of adenosine triphosphate ATP-binding cassette (ABCB5) and multidrug resistance (MDR1) genes expression in acute leukemia: An egyptian study. J Cancer Res Clin Oncol 140: 1323-1330, 2014.

13. Chauhan PS, Bhushan B, Singh LC, Mishra AK, Saluja S, Mittal V, Gupta DK and Kapur S: Expression of genes related to multiple drug resistance and apoptosis in acute leukemia: Response to induction chemotherapy. Exp Mol Pathol 92: 44-49, 2012.

14. Kim HP, Bernard L, Berkowitz J, Nitta J and Hogge DE: Flow cytometry-based assessment of mitoxantrone efflux from leukemic blasts varies with response to induction chemotherapy in acute myeloid leukemia. Cytometry B Clin Cytom 82: 283-294, 2012.

15. Varatharajan S, Abraham A, Karathedath S, Ganesan S, Lakshmi KM, Arthur N, Srivastava VM, George B, Srivastava A, Mathews V and Balasubramanian P: ATP-binding casette transporter expression in acute myeloid leukemia: Association with in vitro cytotoxicity and prognostic markers. Pharmacogenomics 18: 235-244, 2017.

16. Guo Y, Köck K, Ritter CA, Chen ZS, Grube M, Jedlitschky G, Illmer T, Ayres M, Beck JF, Siegmund W, et al: Expression of ABCC-type nucleotide exporters in blasts of adult acute myeloid leukemia: Relation to long-term survival. Clin Cancer Res 15: 1762-1769, 2009.

17. Hauswald S, Duque-Afonso J, Wagner MM, Schertl FM, Lübbert M, Peschel C, Keller U and Licht T: Histone deacetylase inhibitors induce a very broad, pleiotropic anticancer drug resistance phenotype in acute myeloid leukemia cells by modulation of multiple ABC transporter genes. Clin Cancer Res 15: 3705$3715,2009$.

18. Bartholomae S, Gruhn B, Debatin KM, Zimmermann M, Creutzig U, Reinhardt D and Steinbach D: Coexpression of multiple ABC-transporters is strongly associated with treatment response in childhood acute myeloid leukemia. Pediatr Blood Cancer 63: 242-247, 2016.

19. Liu Y, Cui P, Chen J and Li W: Isolation and phenotypic characterization of side population cells in oral squamous cell carcinoma. Mol Med Rep 11: 3642-3646, 2015.

20. Kiehl S, Herkt SC, Richter AM, Fuhrmann L, El-Nikhely N, Seeger W, Savai R and Dammann RH: ABCB4 is frequently epigenetically silenced in human cancers and inhibits tumor growth. Sci Rep 4: 6899, 2014.

21. Zinzi L, Contino M, Cantore M, Capparelli E, Leopoldo M and Colabufo NA: ABC transporters in CSCs membranes as a novel target for treating tumor relapse. Front Pharmacol 5: 163, 2014.

22. Kampen KR, Ter Elst A, Mahmud H, Scherpen FJ, Diks SH, Peppelenbosch MP, de Haas V, Guryev V and de Bont ES: Insights in dynamic kinome reprogramming as a consequence of MEK inhibition in MLL-rearranged AML. Leukemia 28: 589-599, 2014.

23. Chen Y, Bieber MM and Teng NN: Hedgehog signaling regulates drug sensitivity by targeting $\mathrm{ABC}$ transporters $\mathrm{ABCB} 1$ and $\mathrm{ABCG} 2$ in epithelial ovarian cancer. Mol Carcinog 53: 625-634, 2014.

24. Lin CC, Hsu YC, Li YH, Kuo YY, Hou HA, Lan KH, Chen TC, Tzeng YS, Kuo YY, Kao CJ, et al: Higher HOPX expression is associated with distinct clinical and biological features and predicts poor prognosis in de novo acute myeloid leukemia. Haematologica 102: 1044-1053, 2017.

25. Alharbi RA, Pettengell R, Pandha HS and Morgan R: The role of $H O X$ genes in normal hematopoiesis and acute leukemia. Leukemia 27: 1000-1008, 2013. 